\title{
OPTIMASI KEGIATAN PELATIHAN MENGGUNAKAN METODE SIMULASI MONTE CARLO (STUDI KASUS DI BALAI LATIHAN KERJA DINAS TENAGA KERJA DAN TRANSMIGRASI PROVINSI BENGKULU)
}

\author{
Ricky Zulfiandry \\ ricky.zulfiandry@unived.ac.id \\ Universitas Dehasen Bengkulu
}

\begin{abstract}
Abstrak
Provinsi Bengkulu memiliki populasi 1.972.196 penduduk. Yang mana penduduk yang berusia produktif lebih mayoritas dibandingkan dengan yang tidak produktif lagi. Hal ini dilihat dari banyaknya para pencari kerja yang datang mendaftar di dinas pelatihan tenaga kerja dan transmigrasi Provinsi Bengkulu. Hal ini dibutuhkan prediksi jumlah peserta yang mendaftar, sehingga dapat mengoptimalkan waktu dan dana yang tersedia agar dapat melaksanakan pelatihan yang cepat dan tepat sasaran. Untuk memenuhi kebutuhan diatas dapat dilakukan dengan pemodelan dan simulasi. Salah satunya dengan menggunakan metode Monte Carlo.
\end{abstract}

Kata kunci : Monte Carlo, Pemodelan, Simulasi.

\section{Pendahuluan}

Banyaknya peminat pencari kerja, secara tidak langsung menyebabkan pendaftaran pelatihan yang selama ini dilakukan satu bulan sekali harus dilakukan dua bulan sekali. Hal ini dibutuhkan prediksi jumlah peserta yang mendaftar, sehingga dapat mengoptimalkan waktu dan dana yang tersedia agar dapat melaksanakan pelatihan yang cepat dan tepat sasaran. Untuk memenuhi kebutuhan diatas dapat dilakukan dengan permodelan dan simulasi. Salah satunya dengan menggunakan metode Monte Carlo. Metode Monte Carlo dapat menganalisis, memecahkan dan mengoptimalkan berbagai masalah matematika atau fisik melalui sejumlah besar sampel acak statistik untuk simulasi kejadian stokastik[1]. Simulasi Monte Carlo telah banyak digunakan untuk melakukan berbagai penjadwalan proyek. Simulasi Monte Carlo ( Monte Carlo percobaan ) adalah kelas yang luas dari algoritma komputasi yang menggunakan random sampling untuk mendapatkan hasil numerik, biasanya dilakukan simulasi berkali kali untuk mendapatkan distribusi dari entitas probabilistik yang tidak diketahui[2]. Berdasarkan Penelitian yang telah dilakukan, maka ditemukan beberapa masalah dalam penelitian ini bagaimana menerapkan simulasi Monte Carlo pada prediksi peserta pendaftar pelatihan di Balai Latihan Kerja Dinas Tenaga Kerja dan Transmigrasi Provinsi Bengkulu. Permasalahan lainnya bagaimana simulasi Monte Carlo dapat membantu pimpinan Balai Latihan Kerja Dinas Tenaga Kerja dan Transmigrasi Provinsi Bengkulu dalam mengoptimalkan pelaksanaan kegiatan pelatihan.

\section{Metode}

Metodologi penelitian ini memuat gambaran atau langkah - langkah yang akan dilaksanakan dalam melakukan penelitian. Ini perlu ditetapkan supaya penelitian dapat dilakukan dengan terstruktur. Langkah yang akan dilakukan harus mencakup mulai dari mempelajari masalah sampai dengan adanya suatu sistem yang dapat dihasilkan sehingga masalah dapat teratasi.

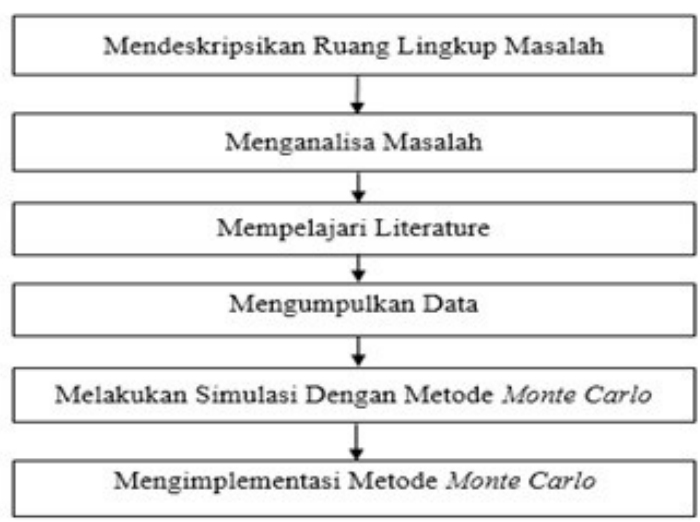

Gambar 1. Kerangka Kerja Penelitian 


\subsection{Menganalisa Masalah}

Langkah analisis masalah adalah untuk dapat memahami masalah yang telah ditentukan ruang lingkup atau batasannya. Dengan menganalisa masalah yang telah ditentukan tersebut, maka diharapkan masalah dapat dipahami dengan baik.

\subsection{Mempelajari Literatur}

Studi literatur adalah tindakan yang dilakukan untuk mempelajari secara ilmiah dan teoritis terhadap masalah-masalah yang telah dibatasi sebelumnya yang bersumber dari buku, jurnal, karya tulis ilmiah, artikel, tesis dan berbagai sumber dari internet oleh para ahli yang dapat dipertanggung jawabkan.

Studi literatur sangat diperlukan agar penelitian yang dilakukan berpijak pada landasan teori yang jelas dan benar yang telah dikemukakan oleh para ahli sebelumnya. Dengan melakukan studi literatur maka penelitian yang dilakukan tidak mengarang dan mengada-ada sehingga dapat diterima didunia ilmu pengetahuan dan masyarakat umum. Kegiatan studi literatur yang dilakukan dalam penelitian ini yaitu:

a. Mempelajari literatur

Literatur yang dipelajari dalam penelitian ini adalah literatur tertulis seperti buku, jurnal, karya tulis ilmiah, artikel, tesis dan berbagai sumber dari internet oleh para ahli yang dapat dipertanggung jawabkan. Literatur yang dipelajari difokuskan kepada teori tentang simulasi dan metode Monte Carlo.

b. Mengamati kondisi di lapangan

Mengamati kondisi dilapangan dilakukan untuk mengamati secara langsung kondisi yang terjadi terhadap sistem yang menjadi objek dalam penelitian ini. Tujuan dilakukannya pengamatan langsung dilapangan adalah agar peneliti dapat mengetahui secara langsung apa yang terjadi pada sistem tersebut dan mengetahui apakah terdapat perbedaan antara teori sistem dengan kenyataan nyata sistem tersebut.

\subsection{Mengumpulkan Data}

Mengumpulkan data dilakukan untuk mengumpulkan semua data-data yang diperlukan dalam penelitian. Teknik yang dilakukan dalam mengumpulkan data dalam penelitian ini adalah dengan teknik observasi dan kalkulasi data. Teknik observasi adalah teknik pengamatan langsung kelapangan dengan dengan mencatat data-data yang diperlukan. Teknik kalkulasi adalah teknik penghitungan data yang tersedia untuk menghasilkan informasi yang berguna didalam penelitian ini.

\subsection{Melakukan Simulasi dengan Metode Monte Carlo}

Mensimulasikan pendaftar peserta pelatihan magang dilakukan untuk memprediksi jumlah peserta yang akan datang. Mensimulasikan berarti mencoba menyesuaikan dengan keadaan sebenarnya secara komputerisasi agar dapat menggambarkan kondisi sistem secara nyata dilapangan. Mensimulasikan peserta pendaftar pelatihan dilakukan dengan tujuan agar dapat memprediksi jumlah pendaftar yang akan mendaftar di masa yang akan datang guna membantu di dalam pengambilan keputusan.

\subsection{Mengimplementasi Metode Monte Carlo}

Mengimplementasikan simulasi metode Monte Carlo, guna mengoptimasi pihak Balai Latihan Kerja Dinas Tenaga Kerja dan Transmigrasi Kota Bengkulu

Di dalam mengambil keputusan pada saat pelaksanaan pelatihan atau saat pelatihan yang akan datang.

\section{Hasil dan Pembahasan}

\subsection{Data Peserta Pelatihan}

Langkah pertama yang dilakukan dalam penelitian ini adalah, peneliti mengumpulkan data peserta pendaftar yang mendaftar periode Januari 2015 - Desember 2015. Adapun data data peserta yang telah mendaftar di Balai Latihan Kerja Dinas Tenaga Kerja dan Transmigrasi Kota Bengkulu di tahun 2015 dapat terlihat pada tabel 1 berikut ini:

Tabel 1. Tabel Peserta Pelatihan 2015

\begin{tabular}{cccc}
\hline Bulan & $\begin{array}{c}\text { Pelaksanaan } \\
\text { Ke }\end{array}$ & $\begin{array}{c}\text { Jumlah Peserta } \\
\text { Yang Mendaftar }\end{array}$ & $\begin{array}{c}\text { Jumlah Peserta } \\
\text { Pelatihan }\end{array}$ \\
\hline Januari & 1 & 18 & 16
\end{tabular}


ILKOM Jurnal Ilmiah Volume 10 Nomor 1 April 2018

\begin{tabular}{|c|c|c|c|}
\hline & 2 & 23 & 16 \\
\hline \multirow[t]{2}{*}{ Februari } & 1 & 21 & 16 \\
\hline & 2 & 19 & 16 \\
\hline \multirow[t]{2}{*}{ Maret } & 1 & 15 & 16 \\
\hline & 2 & 17 & 16 \\
\hline \multirow[t]{2}{*}{ April } & 1 & 25 & 16 \\
\hline & 2 & 11 & 16 \\
\hline \multirow[t]{2}{*}{ Mei } & 1 & 22 & 16 \\
\hline & 2 & 20 & 16 \\
\hline \multirow[t]{2}{*}{ Juni } & 1 & 17 & 16 \\
\hline & 2 & 13 & 16 \\
\hline \multirow[t]{2}{*}{ Juli } & 1 & 25 & 16 \\
\hline & 2 & 10 & 16 \\
\hline \multirow[t]{2}{*}{ Agustus } & 1 & 22 & 16 \\
\hline & 2 & 25 & 16 \\
\hline \multirow[t]{2}{*}{ September } & 1 & 13 & 16 \\
\hline & 2 & 19 & 16 \\
\hline \multirow[t]{2}{*}{ Oktober } & 1 & 21 & 16 \\
\hline & 2 & 14 & 16 \\
\hline \multirow[t]{2}{*}{ Nopember } & 1 & 25 & 16 \\
\hline & 2 & 7 & 16 \\
\hline \multirow[t]{2}{*}{ Desember } & 1 & 19 & 16 \\
\hline & 2 & 17 & 16 \\
\hline
\end{tabular}

Tabel 2. Tabel Distribusi Peserta Pendaftar

\begin{tabular}{cc}
\hline No & $\begin{array}{c}\text { Jumlah Peserta } \\
\text { Pendaftaran }\end{array}$ \\
\hline 1 & 7 \\
2 & 10 \\
3 & 11 \\
4 & 13 \\
5 & 13 \\
6 & 14 \\
7 & 15 \\
8 & 17 \\
9 & 17 \\
10 & 17 \\
11 & 18 \\
12 & 19 \\
13 & 19 \\
14 & 19 \\
15 & 20 \\
16 & 21 \\
17 & 21 \\
18 & 22 \\
19 & 22 \\
20 & 23 \\
21 & 25 \\
22 & 25 \\
23 & 25 \\
24 & 25 \\
\hline
\end{tabular}


Hal pertama yang dilakukan pada simulasi Monte Carlo adalah membuat nilai dari setiap variabel yang merupakan bagian dari model yang dipelajari. Banyak variabel yang mempunyai kemungkinan yang mungkin ingin kita simulasikan. Salah satu cara umum untuk membuat distribusi kemungkinan untuk suatu variabel adalah memperhitungkan hasil di masa lalu. Kemungkinan atau frekuensi relative untuk tiap kemungkinan hasil dari tiap variabel ditentukan dengan membagi frekuensi observasi dengan jumlah total observasi. Kemudian Menentukan Distribusi Kemungkinan dan Kumulatif.

\subsection{Simulasi Monte Carlo}

Model simulasi menggambarkan sistem nyata menjadi sebuah model dalam simulasi yang menggambarkan perilaku, bentuk fisik dan karakteristik lain yang mirip dengan sistem nyata.

Tabel 3. mementukan Distribusi Kemungkinan dan Kumulatif

\begin{tabular}{cccc}
\hline Jumlah Pendaftar & Frekuensi & $\begin{array}{c}\text { Distribusi } \\
\text { Kemungkinan }\end{array}$ & Distribusi Kumulatif \\
\hline 7 & 1 & 0.04 & 0.04 \\
10 & 1 & 0.04 & 0.08 \\
11 & 1 & 0.04 & 0.12 \\
13 & 2 & 0.08 & 0.2 \\
14 & 1 & 0.04 & 0.24 \\
15 & 1 & 0.04 & 0.28 \\
17 & 3 & 0.13 & 0.41 \\
18 & 1 & 0.04 & 0.45 \\
19 & 3 & 0.13 & 0.58 \\
20 & 1 & 0.04 & 0.62 \\
21 & 2 & 0.08 & 0.7 \\
22 & 2 & 0.08 & 0.78 \\
23 & 1 & 0.04 & 0.82 \\
25 & 4 & 0.17 & 1 \\
& 24 & 1.00 & \\
\hline
\end{tabular}

Dari tabel di atas dapat digambarkan distribusi kemungkinan didapat dari jumlah frekuensi dibagi jumlah total frekuensi. Contoh distribusi kemungkinan peserta didapat dari pebagian frekuensi 1 dibagi total frekuensi peserta 24 sehingga hasilnya adalah 0.04. Distribusi kumulatif didapat dari penjumlahan distribusi kemungkinan sebelumnya ditambah dengan distribusi kemungkinan setelahnya dan seterusnya. Kemudian Menentukan interval angka Random untuk setiap variabel. Setelah itu membuat interval angka random.

Tabel 4. menentukan Distribusi Kemungkinan dan Kumulatif

\begin{tabular}{ccc}
\hline No & Jumlah Pendaftar & Frekuensi \\
\hline 1 & 7 & 1 \\
2 & 10 & 1 \\
3 & 11 & 1 \\
4 & 13 & 2 \\
5 & 14 & 1 \\
6 & 15 & 1 \\
7 & 17 & 3 \\
8 & 18 & 1 \\
9 & 19 & 3 \\
10 & 20 & 1 \\
11 & 21 & 2 \\
12 & 22 & 2 \\
13 & 23 & 1 \\
14 & 25 & 4 \\
\hline
\end{tabular}

Dari tabel 2 maka dapat dibuat Frekuensi peserta pendaftar seperti yang terlihat pada tabel 3. Dari tabel diatas jumlah Frekuensi peserta yang mendaftar di tahun 2015 didapat pendaftar 7 peserta 
terjadi sebanyak 1 kali, pendaftar 10 orang sebanyak 1 kali, jumlah pendaftar 11 sebanyak 1 kali, pendaftar 13 orang sebanyak 2 kali, 14 orang sebanyak 1 kali, 15 orang sebanyak 1 kali, 17 orang sebanyak 3 kali, 18 pendaftar sebanyak 1 kali, 19 pendaftar sebanyak 3 kali, 20 orang sebanyak 1 kali, 21 orang sebanyak 2 kali, 22 pendaftar sebanyak 2 kali, 23 pendaftar sebanyak 1 kali, dan 25 orang pendaftar sebanyak 4 kali.

\subsubsection{Menentukan Tabel Distribusi}

Hal pertama yang dilakukan pada simulasi Monte Carlo adalah membuat nilai dari setiap variabel yang merupakan bagian dari model yang dipelajari. Banyak variabel yang mempunyai kemungkinan yang mungkin ingin kita simulasikan. Salah satu cara umum untuk membuat distribusi kemungkinan untuk suatu variabel adalah memperhitungkan hasil di masa lalu. Kemungkinan atau frekuensi relative untuk tiap kemungkinan hasil dari tiap variabel ditentukan dengan membagi frekuensi observasi dengan jumlah total observasi.

\subsubsection{Menentukan Distribusi Kemungkinan dan Kumulatif}

Tabel 5. Distribusi Kemungkinan dan Distribusi Kumulatif

\begin{tabular}{cccc}
\hline $\begin{array}{c}\text { Jumlah } \\
\text { Pendaftar }\end{array}$ & Frekuensi & $\begin{array}{c}\text { Distribusi } \\
\text { Kemungkinan }\end{array}$ & Distribusi Kumulatif \\
\hline 7 & 1 & 0.04 & 0.04 \\
10 & 1 & 0.04 & 0.08 \\
11 & 1 & 0.04 & 0.12 \\
13 & 2 & 0.08 & 0.2 \\
14 & 1 & 0.04 & 0.24 \\
15 & 1 & 0.04 & 0.28 \\
17 & 3 & 0.13 & 0.41 \\
18 & 1 & 0.04 & 0.45 \\
19 & 3 & 0.13 & 0.58 \\
20 & 1 & 0.04 & 0.62 \\
21 & 2 & 0.08 & 0.7 \\
22 & 2 & 0.08 & 0.78 \\
23 & 1 & 0.04 & 0.82 \\
25 & 4 & 0.17 & 1 \\
\hline \multicolumn{5}{c}{1.00} \\
\hline
\end{tabular}

Dari tabel diatas dapat digambarkan distribusi kemungkinan didapat dari jumlah frekuensi dibagi jumlah total frekuensi. Contoh distribusi kemungkinan peserta didapat dari pebagian frekuensi 1 dibagi total frekuensi peserta 24 sehingga hasilnya adalah 0.04 . Distribusi kumulatif didapat dari penjumlahan distribusi kemungkinan sebelumnya ditambah dengan distribusi kemungkinan setelahnya dan seterusnya.

\subsubsection{Menentukan interval angka Random untuk tiap variabel}

Setelah menentukan distrbusi kumulatif untuk tiap variabel yang termasuk dalam simulasi, selanjutnya menentukan batas angka yang mewakili tiap kemungkinan hasil. hal tersebut ditujukan pada interval angka random. Penentuan interval didasari oleh kemungkinan kumulatif.

Tabel 6. Tabel Interval Angka Random

\begin{tabular}{ccccc}
\hline $\begin{array}{c}\text { Jumlah } \\
\text { Pendaftar }\end{array}$ & Frekuensi & $\begin{array}{c}\text { Distribusi } \\
\text { Kemungkinan }\end{array}$ & $\begin{array}{c}\text { Distribusi } \\
\text { Kumulatif }\end{array}$ & Interval \\
\hline 7 & 1 & 0.04 & 0.04 & $00-03$ \\
10 & 1 & 0.04 & 0.08 & $04-07$ \\
11 & 1 & 0.04 & 0.12 & $08-11$ \\
13 & 2 & 0.08 & 0.2 & $12-19$ \\
14 & 1 & 0.04 & 0.24 & $20-23$ \\
15 & 1 & 0.04 & 0.28 & $24-27$ \\
17 & 3 & 0.13 & 0.41 & $28-40$ \\
18 & 1 & 0.04 & 0.45 & $41-44$ \\
\hline
\end{tabular}


ILKOM Jurnal Ilmiah Volume 10 Nomor 1 April 2018

\begin{tabular}{ccccc}
\hline 19 & 3 & 0.13 & 0.58 & $45-57$ \\
20 & 1 & 0.04 & 0.62 & $58-61$ \\
21 & 2 & 0.08 & 0.7 & $62-69$ \\
22 & 2 & 0.08 & 0.78 & $70-77$ \\
23 & 1 & 0.04 & 0.82 & $78-81$ \\
25 & 4 & 0.18 & 1 & $82-99$ \\
\hline
\end{tabular}

Dari tabel di atas dapat digambarkan interval angka random untuk peserta didapat dari distribusi kumulatif. Dimana Distribusi kumulatif dikali dengan 100. Sehingga 0,04 x $100=4$ Sehingga di dapat rentang intervalnya $00-03$ (termasuk 0 dan 3) yang berarti jumlah simulasi pendaftar adalah 7 . Jika bilangan random yang muncul pada interval $04-07$ maka jumlah simulasi pendaftar adalah 10. Begitu seterusnya hingga interval ke 99. Untuk membangkitkan bilangan random, kita bisa menggunakan aplikasi Microsoft Excel dengan menggunakan perintah Randbetween, contoh untuk angka random dari 1- 100, kita tuliskan perintah: = randbetween $(1,100)$ dan diulangi sejumlah baris yang diperlukan. Setelah dapat bilangan random, selanjutnya dapat dilakukan simulasi dari rangkain percobaan.

Tabel 7. Simulasi Percobaan

\begin{tabular}{ccccc}
\hline No & Random & Interval & $\begin{array}{c}\text { Jumlah } \\
\text { Pendaftar }\end{array}$ & $\begin{array}{c}\text { Hasil } \\
\text { Simulasi }\end{array}$ \\
\hline 1 & 20 & $00-03$ & 7 & 13 \\
2 & 6 & $04-07$ & 10 & 10 \\
3 & 40 & $08-12$ & 11 & 17 \\
4 & 11 & $13-20$ & 13 & 11 \\
5 & 43 & $21-24$ & 14 & 18 \\
6 & 13 & $25-28$ & 15 & 13 \\
7 & 7 & $29-41$ & 17 & 10 \\
8 & 30 & $42-45$ & 18 & 17 \\
9 & 40 & $46-57$ & 19 & 17 \\
10 & 36 & $58-62$ & 20 & 17 \\
11 & 43 & $63-70$ & 21 & 18 \\
12 & 27 & $71-78$ & 22 & 15 \\
13 & 27 & $79-82$ & 23 & 15 \\
14 & 21 & $83-99$ & 25 & 14 \\
\hline
\end{tabular}

Dari hasil bilangan random yang dibangkitkan secara acak, maka dapat dilakukan simulasi percobaan dengan mencocokan bilangan random yang muncul dengan tabel interval yang di dapat dari distribusi kumulatif sehingga di dapat hasil simulasi berdasarkan data peserta yang mendaftar. Pada bilangan random pertama yaitu 20 berada pada interval 21 - 24 sehingga di dapat simulasi 13 pada tabel jumlah peserta. Kemudian angka random kedua adalah 6 berada pada interval $4-7$ di dapat nilai simulasi 10. Untuk menguji hasil simulasi sesuai dengan keadaan aktual maka dilakukan uji validitas mengunakan uji perbandingan rata-rata atau means comparison. Model dianggap valid apabila $p$-value $>0,05$.

Tabel 8.Hasil Validasi

\begin{tabular}{lcc}
\hline & Aktual & Simulasi \\
\hline Mean & 16.78571 & 14.71428571 \\
Variance & 28.33516 & 8.065934066 \\
Observations & 14 & 14 \\
Hypothesized Mean Difference & 0 & \\
Df & 20 & \\
t Stat & 1.284626 & \\
P(T<=t) one-tail & 0.106802 & \\
t Critical one-tail & 1.724718 & \\
P $(T<=t)$ two-tail & 0.213603 & \\
T Critical two-tail & 2.085963 & \\
\hline
\end{tabular}


Data dinyatakan valid apabila $p$-value $>0,05$, dari perhitungan didapat $p$-value $=0.106>0,05$ sehingga hasil simulasi dianggap valid dan sesuai dengan keadaan aktual.

\section{Kesimpulan dan Saran}

Berdasarkan pembahasan, implementasi dan pengujian terhadap simulasi sistem yang telah dilakukan, maka peneliti dapat menarik beberapa kesimpulan yaitu sebagai berikut :

1. Penerapan simulasi dengan metode Monte Carlo pada Balai Tenaga Kerja dan Transmigrasi sangat membantu dalam mengoptimalkan kegiatan pelatihan yang akan datang.

2. Metode Monte Carlo dapat membantu pimpinan Balai Tenaga Kerja dan Transmigrasi dalam mengetahui informasi berupa prediksi jumlah pendaftar peserta pelatihan yang kemungkinan terjadi yang nantinya dapat membantu pimpinan Balai Tenaga Kerja dan Transmigrasi di dalam mengambil keputusan.

\section{Daftar Pustaka}

[1] Jianguo Che, at al, "A Monte Carlo Based Robustness Optimization MethodinNewProduct "Design Process: A Case Study, american Journal of Industrial and Business Management, 2014, 4, 360-369 Published Online July 2014 in SciRes.

[2] Winda Nur Cahyo "Pendekatan Simulasi Monte Carlo Untuk Pemilihan Alternatif Dengan Decision Tree Pada Nilai Outcome Yang Probabilistik". Jurnal Teknoin, Volume 13, Nomor 2, Desember 2008, 11-17 ISSN: 0853-8697 